\title{
On the mechanism of two-body abrasive wear in turning "the spin-split theory"
}

\author{
Inge Svenningsson ${ }^{1,2}$ (D) \\ Received: 19 July 2016 / Accepted: 6 March 2017 / Published online: 22 April 2017 \\ (C) The Author(s) 2017. This article is an open access publication
}

\begin{abstract}
This approach regarding metal cutting in steel reveals the likely mechanisms behind a two-body abrasive wear. The theory is based on the assumption that ceramic hard inclusions in the secondary and tertiary cutting zones cannot to any significant extent be deformed plastically. The inclusions, in most cases roundish bullet-type particles, are forced to rotate or break due to the large shear stresses in the cutting zones. A bullet-type particle cannot efficiently cut or wear on the cutting tool rake and tool flank, but when the particle is torn apart, efficient sharp edges are created. Those edges are then, due to the elongation and contraction of the matrix material, pressed out towards the cutting tool, where they, while still rotating, cut until their cutting geometry become less favourable and at that point break into small fragments, which together with the matrix material are welded on the tool clearance and the tool rake faces. Those deposits with particle remnants and chips from the cutting tool contain $30-40 \%$ of ceramic material. The rest is matrix material from the workpiece. The understanding of this mechanism opens new ways to improve cutting materials, both coating and substrate, and the workpiece materials.
\end{abstract}

Keywords Flank wear · Wear mechanisms · Abrasion · Machining $\cdot$ Metal cutting

Inge Svenningsson

inge.svenningsson@driscg.com

Driscg, N. Hasselgatan 15, 81135 Sandviken, Sweden

2 Department of Materials and Manufacturing Technology, Chalmers University of Technology, SE-412 96 Gothenburg, Sweden

\section{Introduction}

\subsection{Wear mechanisms}

The wear rate influences the tool life in metal cutting and has a significant impact on the production cost and productivity. Wear has often a complex nature with more than one active mechanism. Abrasive wear is one of the main types, often involved in combination with other types of wear like adhesion, thermal fatigue, frictional heating, plastic deformation, diffusion and the like. In most deterioration processes, abrasion is present and is in some cases a condition for other types of wear. Examples are as follows:

- First, abrasive wear develops, followed by micro plastic deformation of the abrasive rip and further adhesion, which removes loose parts of the cutting material

- If we could eliminate or decrease the abrasive wear, we would probably decrease other types of wear as well and slow down the total deterioration of the edge.

Abrasive wear is defined as the loss of material due to hard particles or hard protuberances being forced against and moving along a solid surface [1]. Abrasive wear is commonly classified according to the type of contact and the contact environment. The type of contact determines the mode of abrasive wear. The two modes of abrasive wear are known as two-body and three-body abrasive wears. Two-body wear occurs when the hard particles remove material from the opposite surface. The common view is that micro rubbing, micro ploughing, micro cutting or fragmentation removes or displaces material on the surface [2]. Grinding and two-body abrasive wear are similar processes.

This paper deals with only "one type of two-body abrasive wear", wherein 
- A fragment of a hard inclusion cuts into the cutting tool. The fragment is fixed in the matrix of the workpiece material but rotates with the material flow gradients in the secondary (near the tool rake) and tertiary (near the tool flank) cutting zones.

- The application is turning in steel with $\mathrm{Al}_{2} \mathrm{O}_{3}$ CVDcoated carbide cutting tools.

- Other wear mechanisms may occur parallel with abrasive wear but has a minor impact.

- The inclusions are of ceramic-type $\mathrm{Al}_{2} \mathrm{O}_{3}$ or carbides.

- An early stage of the wear propagation is studied. The wear changes with time and goes more complex.

- Mainly, the flank wear is studied.

Most of the hard inclusions in steel are ball shaped or roundish [3] and may cause little abrasive wear on the cutting tool material in their original shape, but efficient cutting edges appear if they fracture into fragments.

The hardness of the $\mathrm{Al}_{2} \mathrm{O}_{3}$ inclusions and the $\mathrm{Al}_{2} \mathrm{O}_{3}$ in the CVD-coated cutting tool is about the same at the same temperature, but the particle fragments can cut in the hard coating due to a lower temperature. The temperature rise in the cutting zone is caused by plastic deformation of the matrix material and some friction. The ceramic inclusions do not follow the plastic matrix in its deformation, and therefore, the temperature rise in those particles has to be performed by transfer. The cutting process is extremely fast, and with current cutting data $\left(v_{\mathrm{c}}=220 \mathrm{~m} / \mathrm{min}\right)$, it is all over in $200 \mu \mathrm{s}$. The ceramic inclusions never reach the same temperature as the cutting tool, at the contact surface in the cutting zones. Ceramic inclusions can, due to higher hardness at lower temperature, cut in the $\mathrm{Al}_{2} \mathrm{O}_{3}$-coated cutting tool.

In other words, hard inclusions (fragments) in the chip material are not softened because they remain in the cutting zone only for a short period of time [4].

The theory is based on the assumption that ceramic hard inclusions in the secondary and tertiary cutting zones cannot to any significant extent be deformed plastically. This assumption is not true in all cases. Ceramic material may, under some specific circumstances, be deformed plastically. It is well known that the top layer of the top coating, ceramic type, is deformed plastically. The ceramic inclusion may probably also be plastically deformed, at least in some parts of the cutting zones, but there are no indicators that this is a dominant factor. We have never found such particles in the chip after machining. The number of plastically deformed ceramic inclusions, if they exist, is likely low compared with those that undergo cracking. Even though they get plastically deformed, they may crack later on, during the cutting process.

R. Bejjani, B. Shi, H. Attia and M. Balazinski [5] describe how broken particles, with a part of them still being in the matrix material, cause abrasive wear.
Frictional wear may be a part of all phases of the two-body abrasive wear. Micro cutting is not always present; the wear may consist of rubbing, ploughing and fragmentation only. Plastic deformation, adhesion, fatigue and more mechanisms may occur around the area affected by abrasion. They may also occur after the abrasion, so what you see are the signs of the last wear mechanism.

The wear on the flank is chosen mainly because the flank wear is predominantly an abrasion phenomenon, evident by the presence of scoring marks on the wear surface [4, 6, 7].

This paper shows a feasible explanation of how, at the beginning of the cutting process, hard and round particles can cut in the cutting tool material.

The materials for the experimental study are chosen based on the size and hardness of the inclusions. The amount or the concentration of hard inclusions is not so important when we study the abrasive scores one by one. Four work materials were selected (see Sect. 4.2 for a more detailed description). They are all often used in cutting tool producers' laboratories for tests and are therefore well known with a lot of data available.

1. EN name, 34 CrNiMo 6 , contains relatively large $\mathrm{Al}_{2} \mathrm{O}_{3}$ inclusions.

2. Sanmac $316 \mathrm{~L}$ is a molybdenum-alloyed austenitic chromium-nickel steel with improved machinability. The material contains small $\mathrm{Al}_{2} \mathrm{O}_{3}$ inclusions.

3. Annealed, EN name, $100 \mathrm{Cr} \mathrm{Mo} 7 \mathrm{3}$, rolling or tool steel. The material contains small carbide inclusions with a size $\leq 1 \mu \mathrm{m}$.

4. EN name, $C 45 R$, pearlitic/ferritic calcium-treated steel.

\section{The model of two-body abrasive wear, the spin-split hypothesis}

The work material, for example steel, always contains a certain amount of hard particles or hard inclusions. The particles, which in most cases are ceramic, cannot to any significant extent be deformed plastically in the secondary and tertiary cutting zones. The inclusions, in most cases roundish bullettype particles, may, due to large shear stresses in the previously mentioned cutting zones, rotate or break into pieces.

The terms and designations regarding metal cutting are in accordance with [8].

\subsection{Step 1, spinning}

The work material flow speeds, $v_{\mathrm{m}}$, are relatively well known, and they can easily be estimated from quick stop tests (see Fig. 1 and [9], page 348). There is a stagnation point near "the edge line", and the speed increases along the tool rake and the 
Fig. 1 Ceramic particles spinning in the secondary and tertiary cutting zones. The size of the particle is exaggerated to make it more visible. The quick test photo to the left shows the material flow in the cutting zone. The $v_{\mathrm{m}}$ arrows are rough estimations taken from the quick stop photo to the left
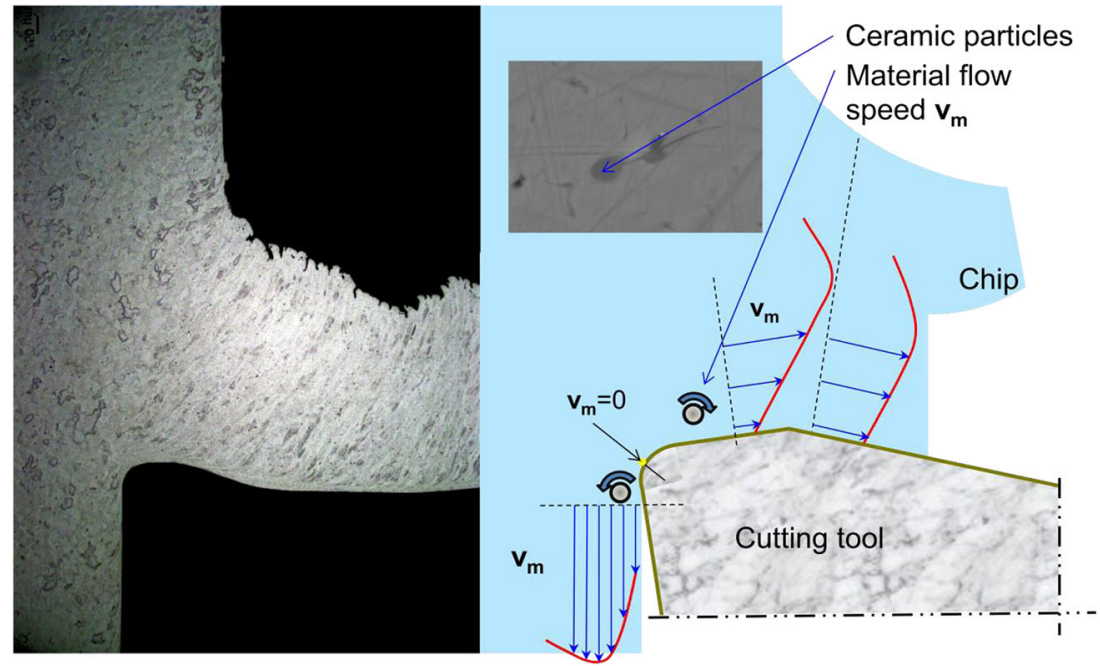

tool flank until the plastic deformation ceases. Perpendicular to the tool flank, the material speed increases through the workpiece until the decreasing diameter towards the centre causes the opposite. Perpendicular to the tool rake, the material flow speed increases up to a zone where the bending of the chip causes a decrease of the speed (see Fig. 1).

These material flow gradients in the secondary cutting zone give rise to rotation of the hardly deformable ceramic particles in the work material. A similar occurrence exists in the tertiary cutting zone. J. Lorent and N. Järvstråt [10] have, by FEM simulation, come to the same conclusion that the particles are spinning, reported in their paper "Round carbide inclusions".

\subsection{Step 2, cracking}

The material flow gradients enforce a high amount of shear stress on the particles. The brittle ceramic inclusions are divided into two pieces (see Fig. 2). The fragments of the inclusion are in this position still harmless; a rounded surface cannot to any significant extent cut in the cutting tool material.

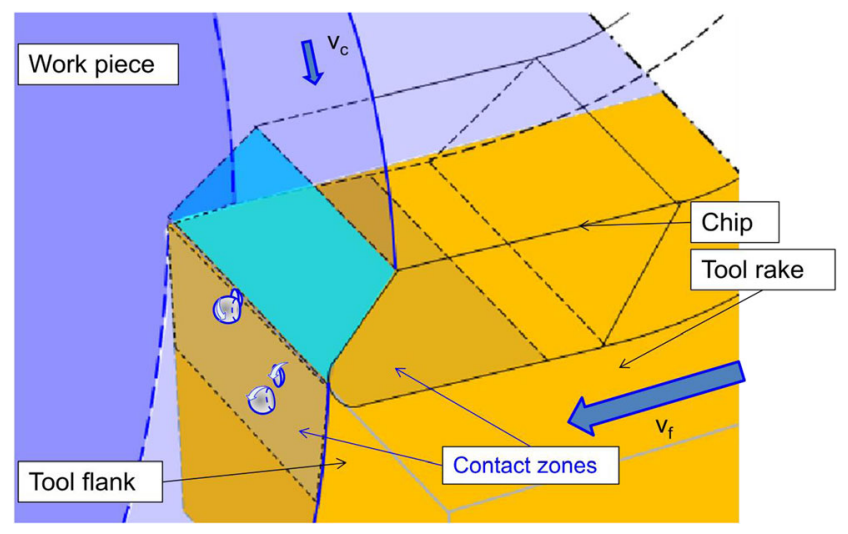

Fig. 2 The ceramic inclusion is, due to high shear stress, divided into two pieces. The size of the particle is exaggerated to make it more visible

\subsection{Step 3, turning after cracking and cutting}

The particle fragment rotates, like the original inclusion, and begins micro cutting when the rotation angle is suitable for this action (see Fig. 3). At the same time, the fragment is pressed towards the cutting tool material due to the elongation of the matrix material in the tertiary cutting zone; the similar occurs in the secondary cutting zone (see Fig. 4).

The inclusions are colder than the matrix material and the top layer on the cutting tool flank and rake. If both the inclusion and the coating are $\mathrm{Al}_{2} \mathrm{O}_{3}$, the inclusion is harder. The reason behind the lower temperature in the inclusions is that most energy transfer is due to plastic deformation of the matrix. The ceramic inclusions do not to any significant extent deform plastically. The temperature rise in them is due to thermal transfer by conduction emanating from the matrix material. Cutting is a very rapid process, with $v_{\mathrm{c}}=220 \mathrm{~m} /$ min and $f_{\mathrm{n}}=0.2 \mathrm{~mm} / \mathrm{r}$; the entire process takes less than $200 \mu \mathrm{s}$ from the un-deformed workpiece material to the end of the contact zone where the plastic deformation ceases. It is likely that most processes involved in making the chip

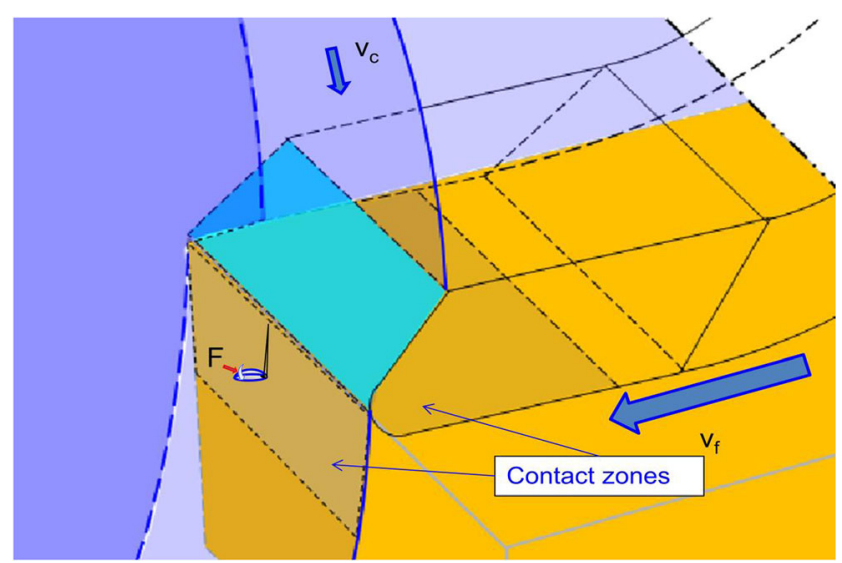

Fig. 3 The fragment has turned to the right position for cutting into the tool material 


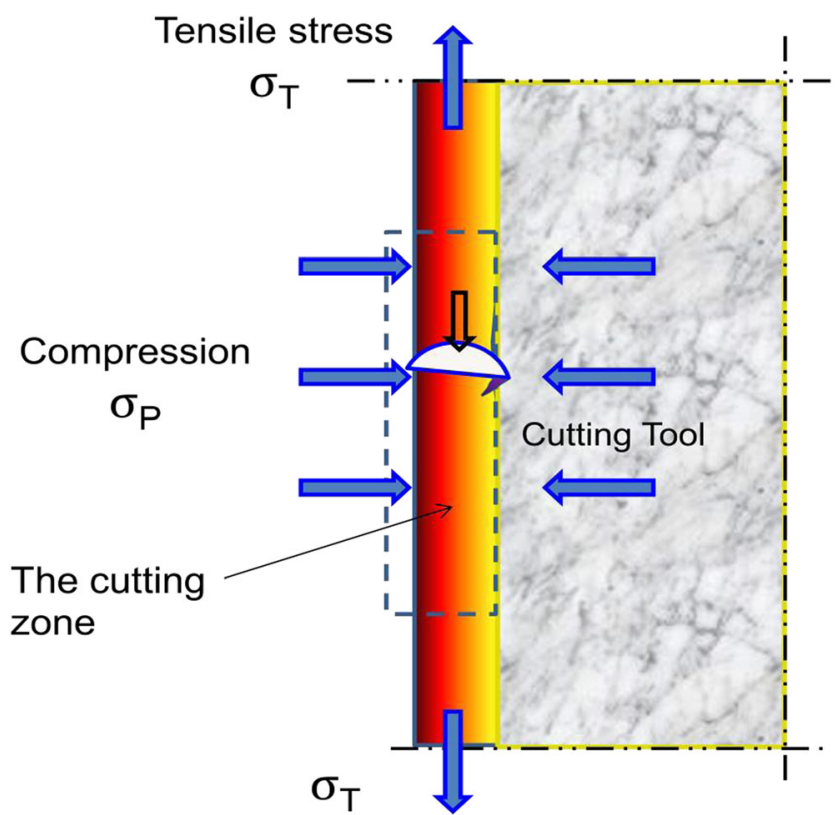

Fig. 4 When the matrix material gets stretched in the tertiary cutting zone, the fragment is pressed against the cutting material and starts to cut

material and the top layer of the workpiece do not have the time to reach steady-state condition.

\subsection{Step 4, turning continues, cutting with a more negative rake angle}

When the rotation makes the fragment rake angle more negative and less light cutting, the cut score gets narrower. The result is a diamond-shaped score (see Fig. 5).

\subsection{Step 5, turning continues, fracturing}

When the rake angle on the fragment gets too negative and the clearance too high, the stress exceeds the limits and the fragment

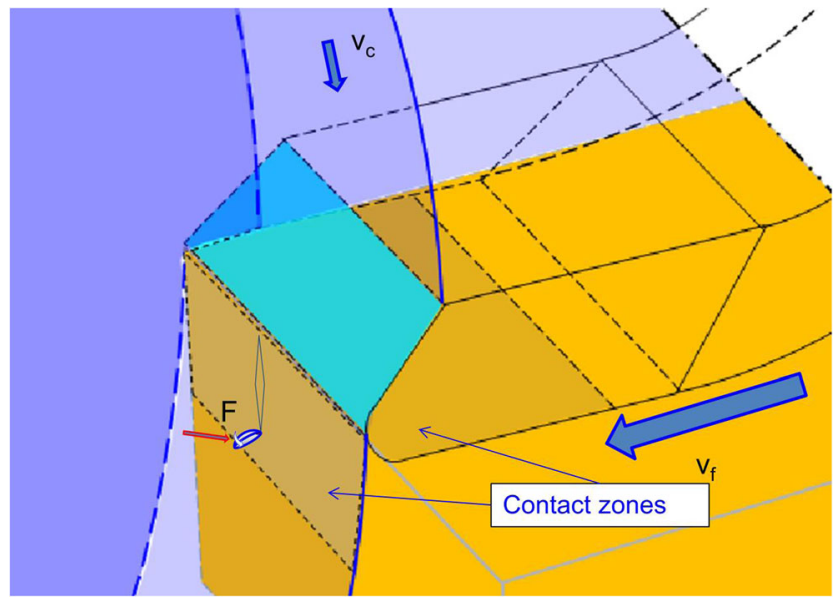

Fig. 5 The splinter cuts a diamond-shaped score when cutting with a more negative rake angle. This shape of abrasive wear is very common in metal cutting

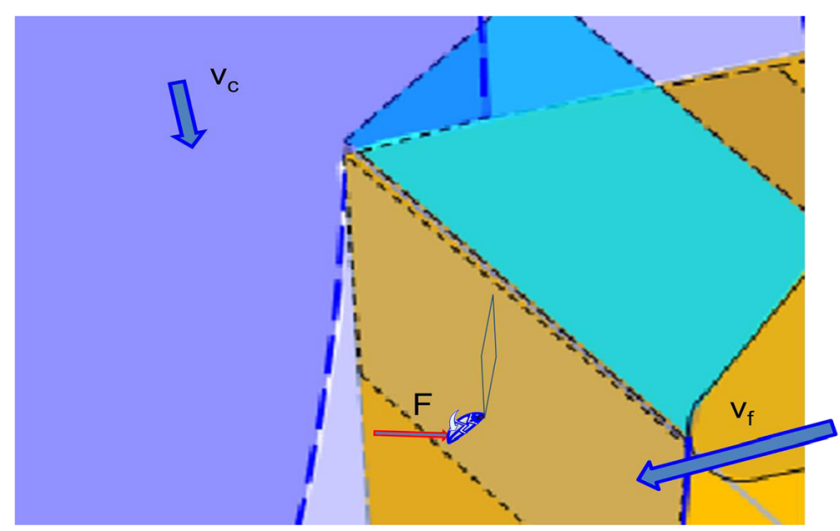

Fig. 6 Fracturing

starts to fracture (see Fig. 6). At least some parts of the fragments splits. The remnants together with "chips from the coating" and matrix material are then welded onto the tool flank at the end of the diamond rip (see Fig. 7). Some of the fragment parts remain in the workpiece surface, i.e. the newly cut surface.

\section{Experimental procedure}

\subsection{Experimental approach}

The aims are firstly to verify the hypothesis in metal cutting and secondly to evaluate if this is a likely mechanism behind the current two-body abrasive wear.

The approach is to study the wear pattern and the workpiece materials before the cut, during the cut (by quick stop tests) and after the cut in order to determine whether the mechanisms earlier fit in or not. By means of current cutting data, some basic knowledge regarding cutting, the dimensions of the abrasive rip and the size of the inclusion, we can calculate the average rotational speed of the particle fragment, $n_{\mathrm{p}}$.

This rotational speed can then be compared with the speed that we get if we would let the fragment rotate with the plastic deformation in the tertiary cutting zone near the surface and the

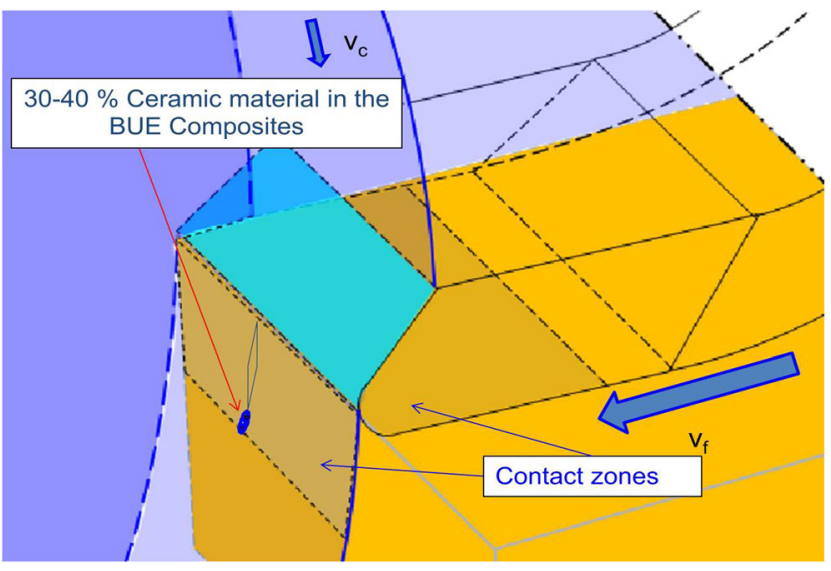

Fig. 7 The remnants of the particle fragment welded on the tool flank 


\section{Number of spherical carbides}

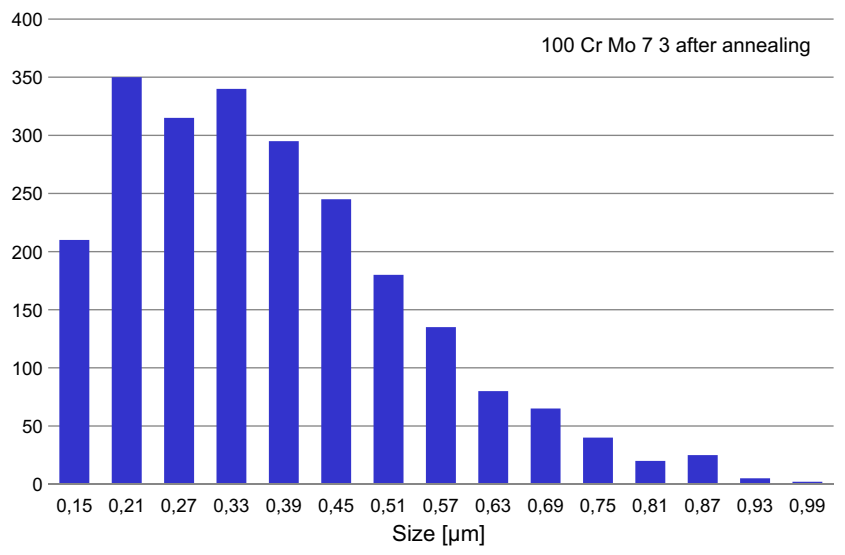

Fig. 8 Size distribution of carbides in $100 \mathrm{Cr}$ Mo 73 after annealing

wear zone $n_{\mathrm{px}}$. Another way is, to see what rotational speed, $n_{\mathrm{PW}}$, we get if a round particle would rotate freely between the workpiece and the cutting tool flank. It should be higher than $n_{\mathrm{P}}$.

If the calculated rotational speeds have the same magnitude, we can conclude that the mechanism according to this hypothesis is possible. In studying more types of work materials in combination with other observations, we can confirm the thesis or find it more or less probable.

\subsection{The materials chosen for the experimental study}

- EN name, 34CrNiMo 6, contains relatively large $\mathrm{Al}_{2} \mathrm{O}_{3}$ inclusions. The larger ones are in the range of $1-10 \mu \mathrm{m}$, by volume $500-1000 \mathrm{ppm}$. The average hardness is 285 HB; the matrix material is tempered martensite (see Figs. 8 and 9). The producer is Ovako Imatra Oy, Finland.

$\begin{array}{lllllll}\mathrm{C} & \mathrm{Si} & \mathrm{Mn} & \mathrm{Smax} & \mathrm{Cr} & \mathrm{Mo} & \mathrm{Ni} \\ 0.34 & 0.30 & 0.70 & 0.035 & 1.5 & 0.20 & 1.5\end{array}$

Number of spherical carbides

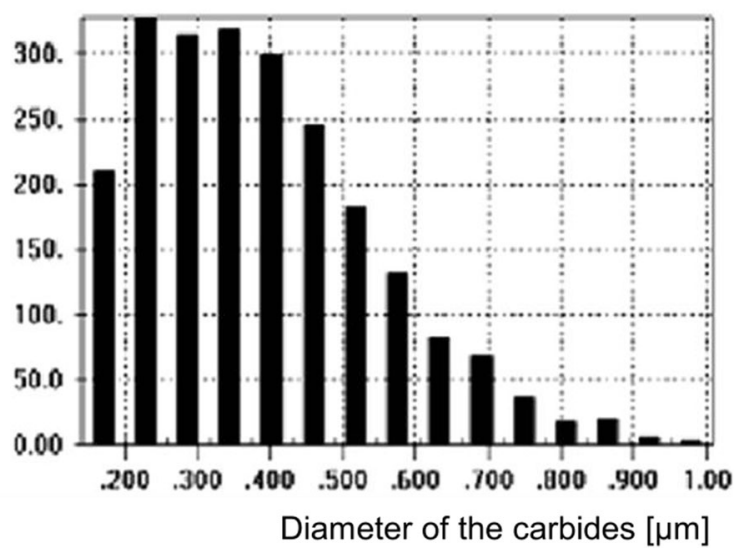

Fig. 9 Workpiece material 34CrNiMo 6, $285 \mathrm{HB}$, which is polished and etched with $2 \%$ of Nital. The black spots are $\mathrm{Al}_{2} \mathrm{O}_{3}$ or cavities after $\mathrm{Al}_{2} \mathrm{O}_{3}$ inclusions. They are non-circular
- Sanmac $316 \mathrm{~L}$ is a molybdenum-alloyed austenitic chromium-nickel steel with improved machinability; the producer is Sandvik, Sweden. The material contains $\mathrm{Al}_{2} \mathrm{O}_{3}$ inclusions. The larger ones are in the range of 200-300 nm.

$\begin{array}{llllllll}\mathrm{C} & \mathrm{Si} & \mathrm{Mn} & \mathrm{P} & \mathrm{Smax} & \mathrm{Cr} & \mathrm{Mo} & \mathrm{Ni} \\ \leq 0.03 & 0.30 & 1.8 & \leq 0.04 & 0.030 & 17 & 2.1 & 10\end{array}$

- Annealed, EN name, 100 Cr Mo 7 3. Rolling or tool steel produced by OVAKO Sweden AB. The material contains carbide inclusions with a size $\leq 1 \mu \mathrm{m}$, average size $=0.39 \mu \mathrm{m}$, by volume $14 \%$. It also contains $\mathrm{Al}_{2} \mathrm{O}_{3}$ inclusions in the same range, but the amount is much lower.

$\begin{array}{lllll}\mathrm{C} & \mathrm{Si} & \mathrm{Mn} & \mathrm{Cr} & \mathrm{Mo} \\ 0.97 & 0.30 & 0.70 & 1.8 & 0.25\end{array}$

- EN name, C45R, pearlitic/ferritic calcium-treated steel produced by Huta Bankova in Poland. The calcium treatment has made the $\mathrm{Al}_{2} \mathrm{O}_{3}$ inclusions less effective as abrasive "tool".

$\begin{array}{llllllllll}\mathrm{C} & \mathrm{Si} & \mathrm{Mn} & \mathrm{P} & \mathrm{S} & \mathrm{Cr} & \mathrm{Mo} & \mathrm{Ni} & \mathrm{Cu} & (\%) \\ 0.44 & 0.23 & 0.75 & 0.009 & 0.021 & 0.08 & 0.003 & 0.03 & 0.04 & \\ \mathrm{Al} & & & & & & & & & \\ 0.032 & & & & & & & & & \end{array}$

\section{Results}

\subsection{Abrasive wear in turning, after $10 \mathrm{~min}$ of machining} in 34CrNiMo $6[8,11]$

The wear (see Fig. 10) contains a large number of rips. From the width of those rips, we can roughly estimate the size of the objects that have cut them. With a measured width of $4 \mu \mathrm{m}$, we can conclude the splinter has had a size bigger than that. Looking at the wear pattern, we can estimate the size to be around 6-7 $\mu \mathrm{m}$, which is in line with the inclusion size shown in Fig. 9.

\subsubsection{Calculation of the average rotational speed}

An approximation of how the rotation develops is that, just after the splitting, it slows down, and when the second part of the particle is removed and the fragment starts to cut, it accelerates.

If we assume that

1. The contact zones between the work material and the cutting tool are defined as the zones where there is a physical contact. This area is not constant over time, but 
Fig. 10 Wear after 10 min of machining in $34 \mathrm{CrNiMo}$

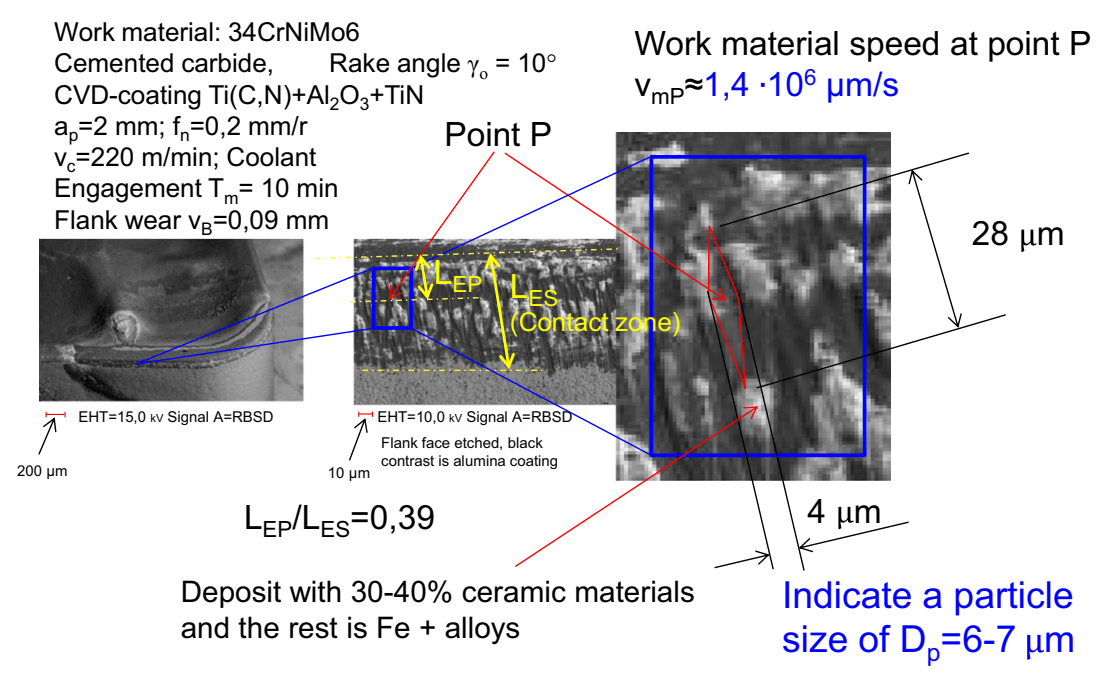

it varies according to the segmentation of the chip and other dynamic processes.

2. The material speed at the stagnation zone near the flank is zero, and the material speed is the cutting speed at the point where the contact zone ends. This is not $100 \%$ correct; the length of the area undergoing plastic deformation is a bit longer.

3. The material speed increases linearly from the stagnation point to the point where the contact ceases.

4. The fragment centre has along the rip the same speed as the work material speed at the point $P$ (see Figs. 10 and 11).

$v_{\mathrm{mP}} \approx v_{\mathrm{c}} \cdot L_{\mathrm{EP}} / L_{\mathrm{ES}}=3.66710^{6} \cdot 0.39=1.43 \cdot 10^{6} \mu \mathrm{m} / \mathrm{s}$
5. The fragment starts to cut at $-15^{\circ}$ rake angle and ends at $60^{\circ}$

6. Rotation during the cut $=75^{\circ}$, part of the rev. $k=75 /$ $360=0.2083$

7. Particle diameter $D_{\mathrm{p}}=7 \mu \mathrm{m}$

We get the following:

Time for the cut $t_{\mathrm{c}}=L_{\mathrm{c}} / v_{\mathrm{mP}}=31.5 /\left(1.43 \cdot 10^{6}\right)$

$$
=22.0 \cdot 10^{-6} \mathrm{~s}
$$

Time for one revolution $t_{\mathrm{R}}=t_{\mathrm{c}} / k$

$$
=22.0 \cdot 10^{-6} / 0.2083=106 \cdot 10^{-6} \mathrm{~s}=>n_{\mathrm{P}}=9400 \mathrm{rps}
$$

Fig. 11 Particle spin in 34 CrNiMo6, cutting data, etc. (see Fig. 10)

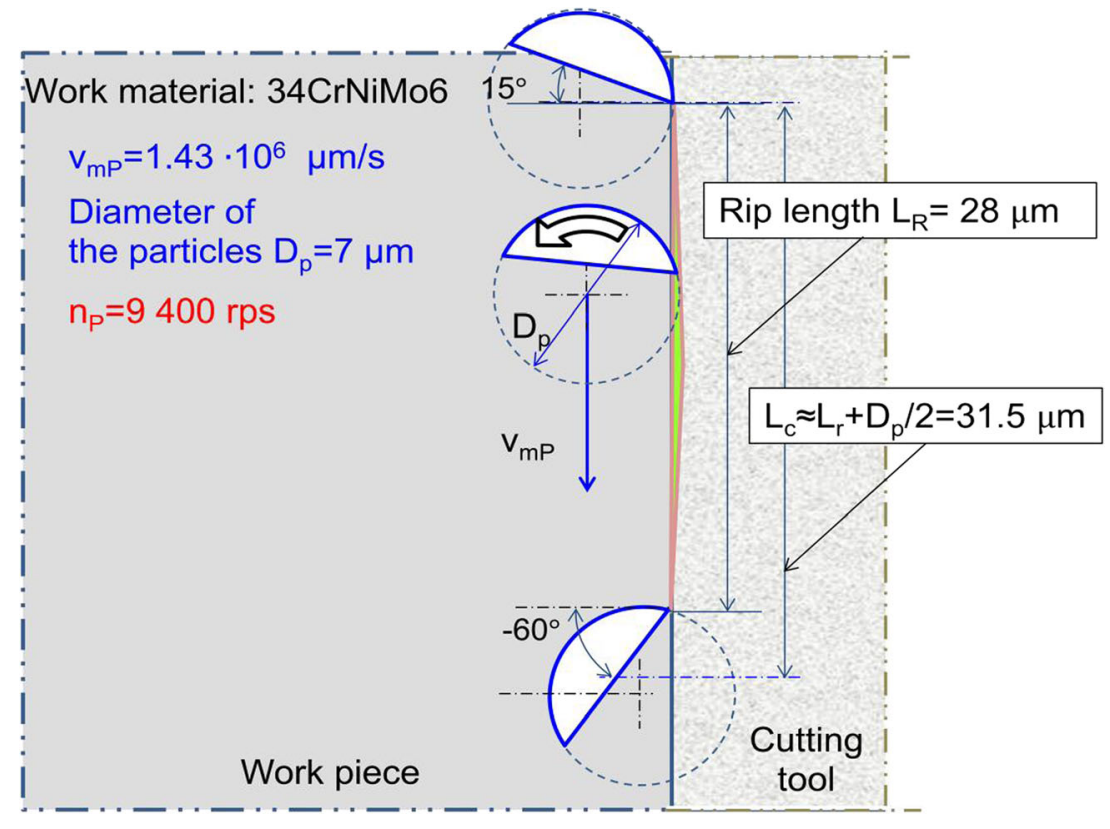


Fig. 12 Rolling particle between the workpiece and the tool flank

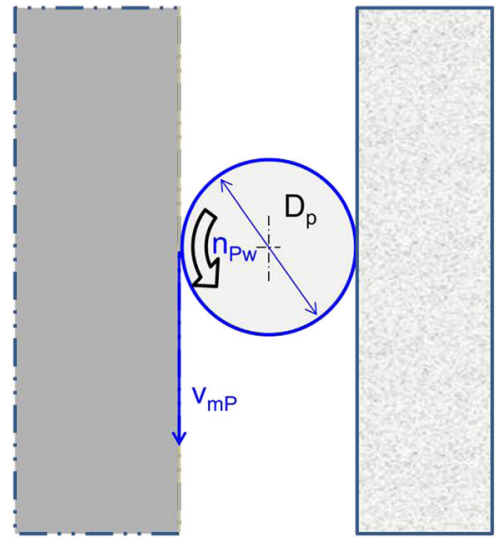

Diameter of the particle $D_{p}=7 \mu \mathrm{m}$

Work material speed $\mathrm{v}_{\mathrm{mP}}=1.4 \cdot 10^{6} \mu \mathrm{m} / \mathrm{s}$

Particle rotational speed between the work piece and the tool flank, $\mathrm{n}_{\mathrm{Pw}}=32 \cdot 10^{3} \mathrm{rps}$
We then get that the fragment has an average spin speed of $n_{\mathrm{p}}=9400 \mathrm{rps}$ (see Figs. 10 and 11). It has lower spin speed at the beginning of the rip and higher at the end.

The time for cutting one rip is $22 \mu \mathrm{s}$.

The rotational speed is "very" high but should be compared with the rotational speed that we would get if we let the particle roll between the workpiece and the tool flank, $n_{\mathrm{Pw}}$ (see Fig. 12).

$n_{\mathrm{Pw}}=v_{\mathrm{mP}} /\left(2 \pi D_{\mathrm{p}}\right) \approx 3210^{3} \mathrm{rps}$

A rough estimation of the rolling speed just before the cracking (see Fig. 12) has the assumption that

- The tertiary cutting zone is $50 \mu \mathrm{m}$ thick (see Fig. 13).

- The material speed gradients are linear.

The assumptions give us a rotational speed of $n_{\mathrm{Pw}=} \Delta v /\left(2 \pi D_{\mathrm{p}}\right)=0.22 \cdot 10^{6} /(2 \pi \cdot 7)=5000 \mathrm{rps}$

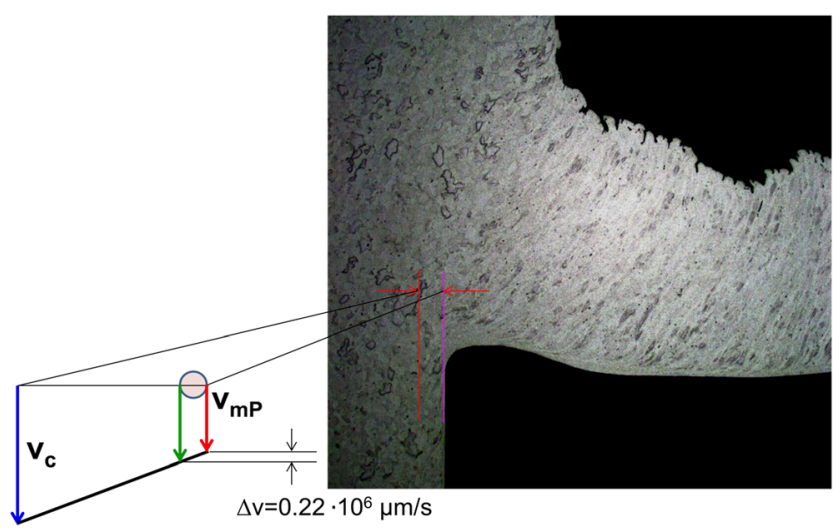

Fig. 13 Rotational speed just before cracking with the same cutting data as in Fig. 10
In other words, the rotational speed just before it cuts has the same magnitude as the previously mentioned $n_{\mathrm{P}}=9400 \mathrm{rps}$.

At the end of the rip, there is a "deposit" of material welded on the flank, which contains $30-40 \%$ of ceramic material; the rest is $\mathrm{Fe}+$ alloys. It is likely that it is the remnants of fragments and chips from the micro cutting. Of interest is that those deposits seem to be untouched except when a fragment has cut through them. An explanation could be that the matrix material is only partially in contact with the cutting tool material, like sandpaper but with long distances between the grains (see Sect. 5).

With the same assumptions regarding the rake, we get half the rotational speeds in steel due to the chip thickness ratio, which is about 2 (the chip thickness is two times the uncut chip thickness) [9]. The chip will be about two times thicker than the uncut chip thickness, and the material flow speed at the point where the plastic deformation ceases is about $v_{\mathrm{c}} / 2$.

The material also contains carbides with a size of $1 \mu \mathrm{m}$. There is no sign of wear caused by that size of objects, which is not so strange. The larger ceramic particle fragments are cutting at a distance from the matrix material, pressing the tool away. The smaller fragments from the carbides will never reach the cutting tool surface (sticking out less than the larger fragments from $\mathrm{Al}_{2} \mathrm{O}_{3}$ ).

\subsection{Abrasive wear, in turning, after $\mathbf{1 0}$ min of machining in Sandvik Sanmac 316L}

Using the same assumptions and calculations for the work material, Sanmac 316L (see Fig. 14), we get the following:

The average diameter of the particles is $D_{\mathrm{p}}=260 \mathrm{~nm}$ (taken from the wear pattern and the average diameter from a sample where the smallest is $<50 \mathrm{~nm}$; those smaller than $50 \mathrm{~nm}$ were not able to be extracted).

Spin speed $n_{\mathrm{p}}=150,000 \mathrm{rps}$ 
Fig. 14 Wear pattern after turning, 10 min, in Sanmac 316L, secondary mode

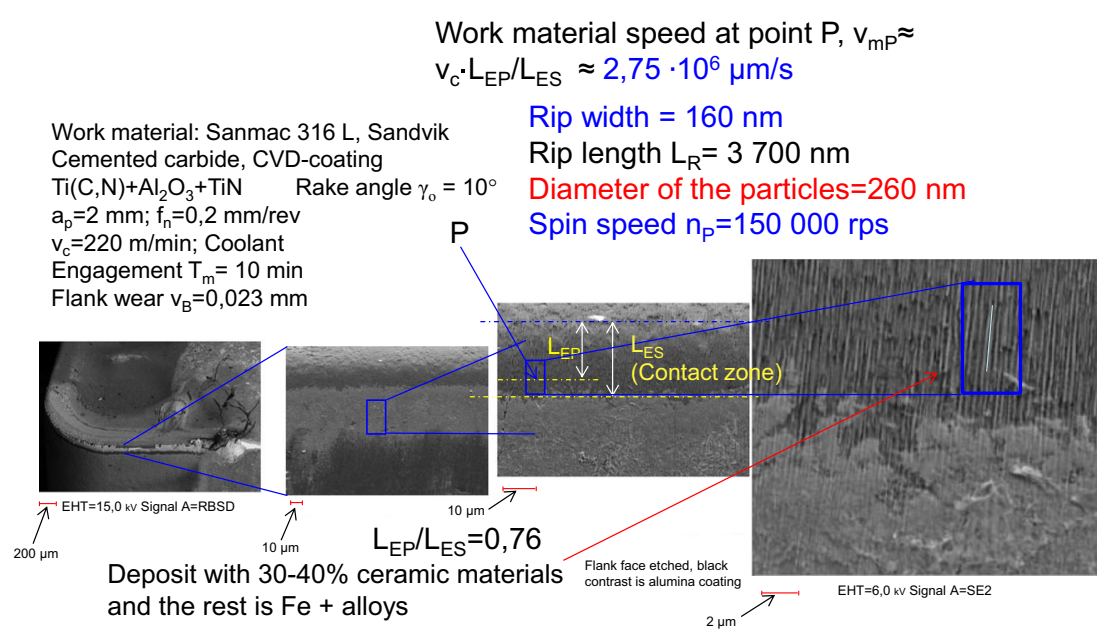

It is very similar to the previous material, 34CrNiMo 6, but everything is a lot smaller. The material in the particles is $\mathrm{Al}_{2} \mathrm{O}_{3}$ (complex type) and is at current temperature harder than the hotter aluminium oxide coating on the cutting tool. The abrasive wear rate is lower than in $34 \mathrm{CrNiMo} 6$; according to [12], the wear rate decreases substantially when the size of the wearing particles gets smaller.

\subsection{Abrasive wear in turning, after 10 min of machining in annealed $100 \mathrm{Cr}$ Mo 73}

The work material is an annealed ball bearing steel, relatively free from $\mathrm{Al}_{2} \mathrm{O}_{3}$. The amount of $\mathrm{Al}_{2} \mathrm{O}_{3}$ inclusions is some magnitudes less than the amount of carbides, by volume $14 \%$. The diameters of the carbides are $\leq 1 \mu \mathrm{m}$. It looks like wear caused by micro plastic deformation, but in higher magnification, clear marks from cutting are visible, and micro plastic deformation and frictional heating are likely also present. The wear pattern is in this case caused by carbides and is similar to the ones of the first two materials but with some differences (see Fig. 15):

- The rips are longer.

- No clear deposits at the end of the rips were found.

- The width of the rip can be larger than the diameter of the carbides (see Fig. 8).

A possible conclusion is that the large amount of carbides in the work material makes that more than one fragment cuts the same rip. It could also be that the three-body abrasive wear has polished the surface on the area closest to the workpiece material.

\subsection{Abrasive wear, in turning, after $\mathbf{1 0}$ min of machining in C45R}

C45R has a ferritic and pearlitic structure and contains $\mathrm{Al}_{2} \mathrm{O}_{3}$ inclusions and is calcium treated. The pearlite grains probably
Fig. 15 Wear pattern after turning, 10 min in annealed 100 Cr Mo 7 3, backscatter mode

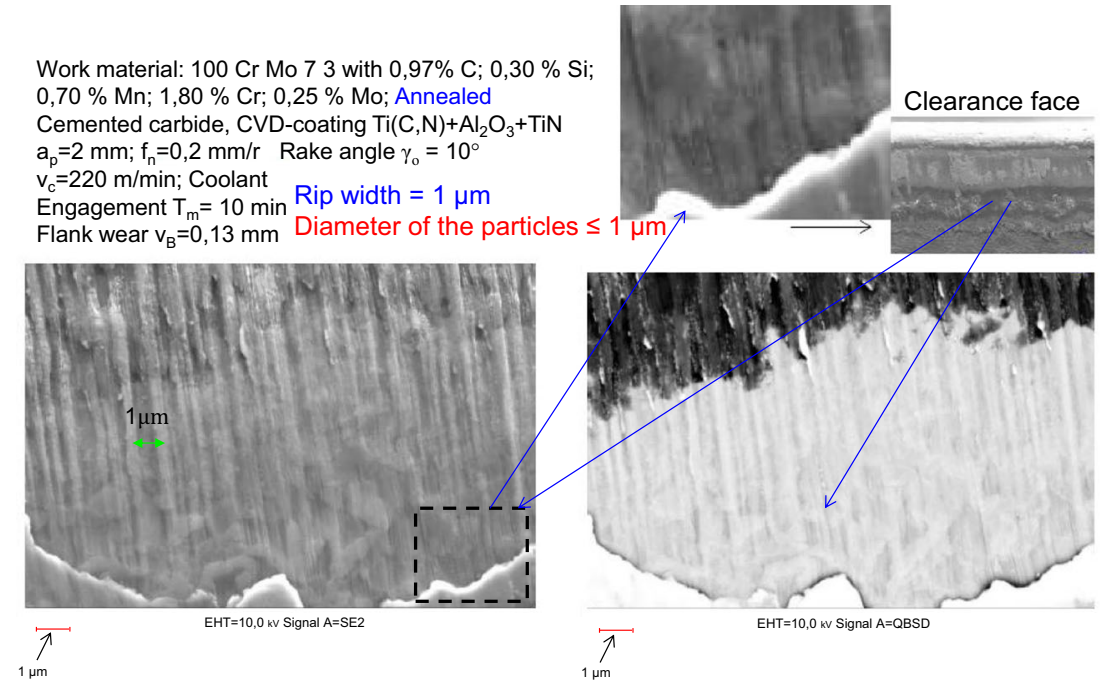


Fig. 16 Wear pattern after turning, 10 min, in C45R, backscatter mode
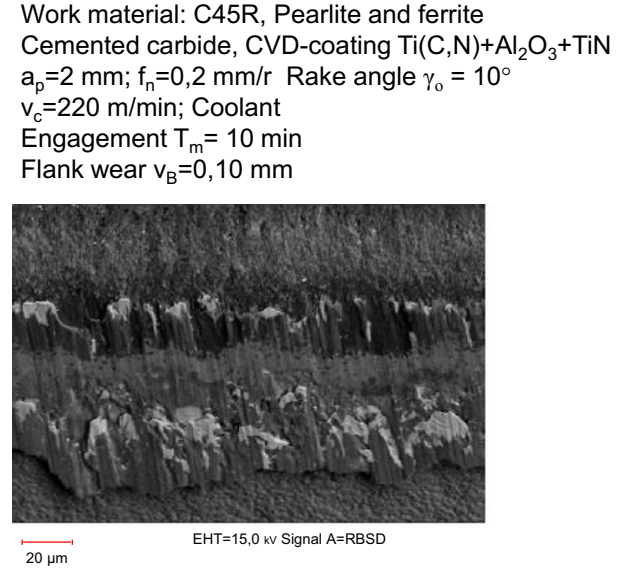

Smearing on face(not etched)

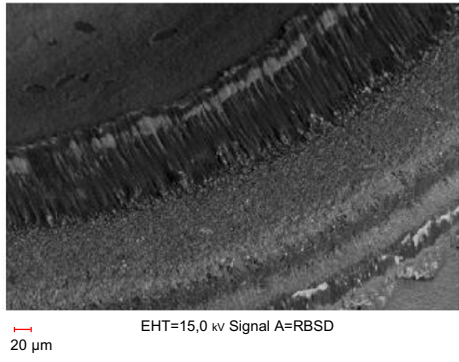

Smearing on face(not etched) break into very small fragments, and the wear from them is therefore not visible at the current magnification.

The wear pattern is without rips and could be a threebody abrasive wear $[2,13]$. The pearlitic structure also causes wear, but also other wear mechanisms are likely present (see Fig. 16). A deposit occurred at the end of the contact zone. A plausible explanation is that the calcium treatment has undermined the inclusions, which made the inclusion fragments less capable of cutting, making them softer or more brittle. When they collapse early, the matrix material comes closer to the cutting tool material and moves the fragment remnants out from the cutting zone. The deposit contains $40 \%$ of ceramic material.

\subsection{The machined surface, generated after the edge line}

The surface generated by the cutting edge, opposite the flank, is stretched and plastically deformed (see Fig. 17). The black

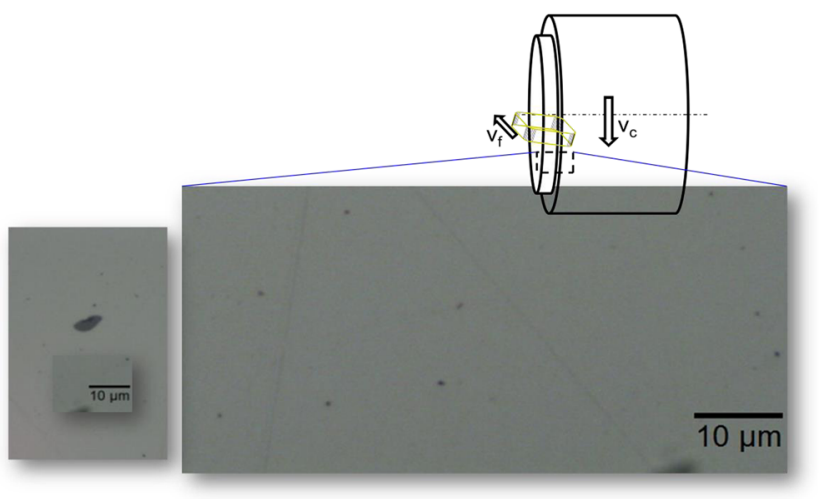

Fig. 17 The workpiece surface generated after the edge line. The black spots are cavities; the size is in the range of $1 \mu \mathrm{m}$ in diameter. The shapes are, in most cases, non-circular. The larger cavity to the left could be from a particle fragment which has cut into the cutting tool material earlier and which is left after fracture. The workpiece material is $34 \mathrm{CrNiMo6}$. Preparation of the sample: polished 5 min with $9-\mu \mathrm{m}$ diamond, $5 \mathrm{~min}$ with $3-\mu \mathrm{m}$ diamond, 5 min with $1-\mu \mathrm{m}$ diamond and 5 min with $\mathrm{SiO}_{2}$ suspension, and removed depth is $2-5 \mu \mathrm{m}$ spots are cavities in which small hard inclusions have been enclosed. The shapes are, in most cases, non-circular. They are likely pieces from the larger original fragment with the size of approximately 5-6 $\mu \mathrm{m}$. The fragments fly away when the surface deforms plastically. The larger cavity to the left could be from a particle fragment, which has been micro cutting in the tool material earlier.

\subsection{Nominal micro chip thickness}

The depth of the rip in Fig. 10, 34CrNiMo 6, is $800 \mathrm{~nm}$ at the largest width of the rip, which should be approximately the nominal micro chip thickness of the cut (see Fig. 18). With the edge radius taken from the fragments in Fig. 17, found to be $50-100 \mathrm{~nm}$, we get appropriate conditions for cutting. About ten times the edge radius in nominal chip thickness is what the tool suppliers recommend for turning in most materials to be cut.

It is hard to tell from the current photos what type of abrasive wear mechanisms that have been involved in the removal of the tool material. But with a chip thickness ten times the edge radius, it is likely that micro cutting plays a dominant roll, but frictional wear, plastic deformation, adhesion and others are likely also present. In the beginning of the rip, frictional wear could be dominant.

\subsection{Summary of the results}

It is not the hard inclusions in their original shapes that cause a two-body abrasive wear. It is the fragments from the hard inclusions, created when the inclusions are torn apart in the secondary and tertiary cutting zones, which cut in the cutting tool material.

The largest fragments, most likely from the largest inclusions, cause the abrasive wear. Smaller fragments, from smaller inclusions, cannot reach the cutting tool due to the larger 
Fig. 18 Maximum nominal micro chip thickness when the fragment cuts at maximum depth

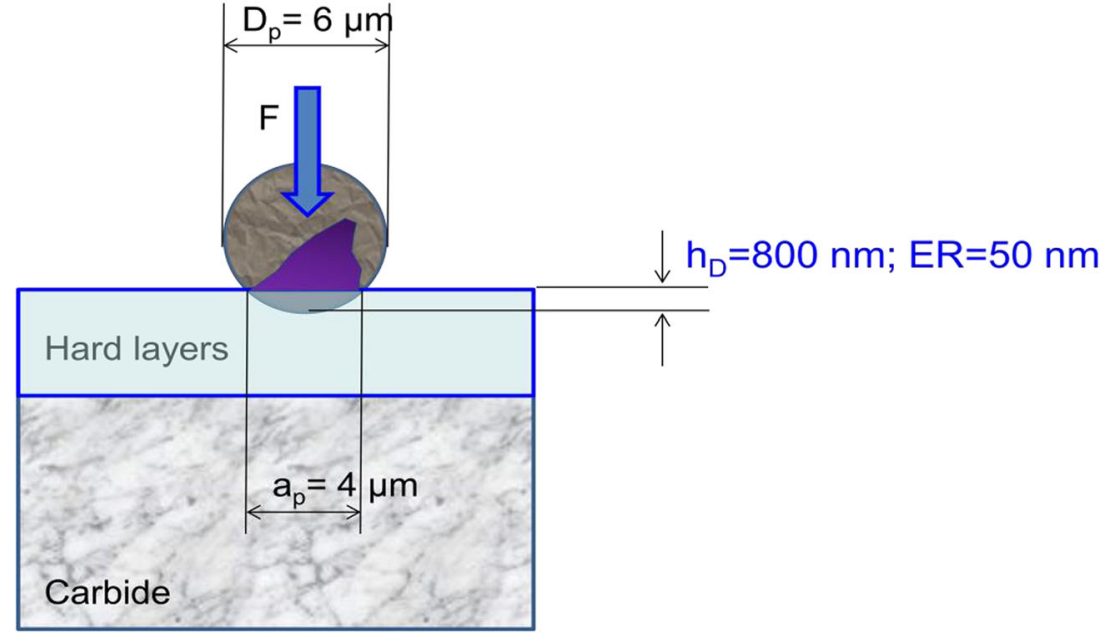

fragments sticking out longer, pressing the cutting tool away from the matrix.

This type of two-body abrasive wear can be generated not only by $\mathrm{Al}_{2} \mathrm{O}_{3}$ but also by spherical carbides. Probably all types of hard inclusions can wear in this way if they are large and brittle enough to break.

The performed tests show, for the first three work materials, the same wear pattern was expected by the hypothesis. The magnitude of the fragment rotational speed has been found to correspond to other possible spin speeds and rotational speeds just before cracking and rolling particle between the workpiece and the tool flank.

The time for cutting one rip in 34CrNiMo6 was found to be $t_{\mathrm{c}}=22 \mu \mathrm{s}$. The average particle rotational speed was as follows:

$n_{\mathrm{P}}=9400 \mathrm{rps}$ with an estimated particle size of $7 \mu \mathrm{m}$. In Sanmac $316 \mathrm{~L}$, we got $t_{\mathrm{c}}=1.39 \cdot 10^{-6} \mu \mathrm{s}$ and : $n_{\mathrm{P}}=150,000 \mathrm{rps}$ and a particle size of $260 \mathrm{~nm}$.

The values are extremely high regarding the spin speed and low regarding the time space for making a rip but that is often the case in metal cutting. The process is fast; everything happens within about $200 \mu$ s with the existing current cutting data.

The calculation of the particle speed is not so accurate, but the magnitude is likely correct.

Smaller fragments from the original fragment were found in the machined surface together with the major part of the fragments. The shapes are, in most cases, non-circular. There is nothing else that can generate such cavities in 34CrNiMo6. This is an indication that the hypothesis might be correct. A larger cavity from a particle fragment, which is believed to have been micro cutting in the tool material earlier, was also found.

\section{Discussion}

\subsection{Another possibility}

Another explanation that meets the observations is that the inclusions split when they hit the cutting tool surface. It does not alter things but is a possibility.

\subsection{Theoretical simulations of the abrasive wear rate and temperature}

Simulations of the abrasive wear rate and the temperature are possible; we need specific cutting forces for an $\mathrm{Al}_{2} \mathrm{O}_{3}$ fragment cutting in the $\mathrm{Al}_{2} \mathrm{O}_{3}$ coating at current temperatures. It can be used to evaluate the wear rate versus different particle sizes and concentrations or to optimize the cutting tool materials, coating and substrate.

When we then have the micro cutting force, we can further calculate the temperature around the micro cutting edge.

\subsection{Engineered work materials with improved machinability}

If we consider a type of steel where $\mathrm{Al}_{2} \mathrm{O}_{3}$ inclusions give rise to abrasive wear and the fact that only the largest fragments cut in the cutting tool, we can decrease the wear rate by adding larger particles of a less hard material; they could be carbides or other materials that we have access to. Another way is to make particles aside and later on add them to the liquid steel. Those particles could be made of $\mathrm{Al}_{2} \mathrm{O}_{3}$ in the centre but with a softer surface. This makes them less effective when they cut in the cutting tool material. It could be an alternative instead of calcium treatment. 
Fig. 19 The particle fragment cutting action with hard $\mathrm{Al}_{2} \mathrm{O}_{3}$ coating to the left and a more elastic thicker layer underneath the hard $\mathrm{Al}_{2} \mathrm{O}_{3}$ coating to the right. All deformations are assumed to be elastic
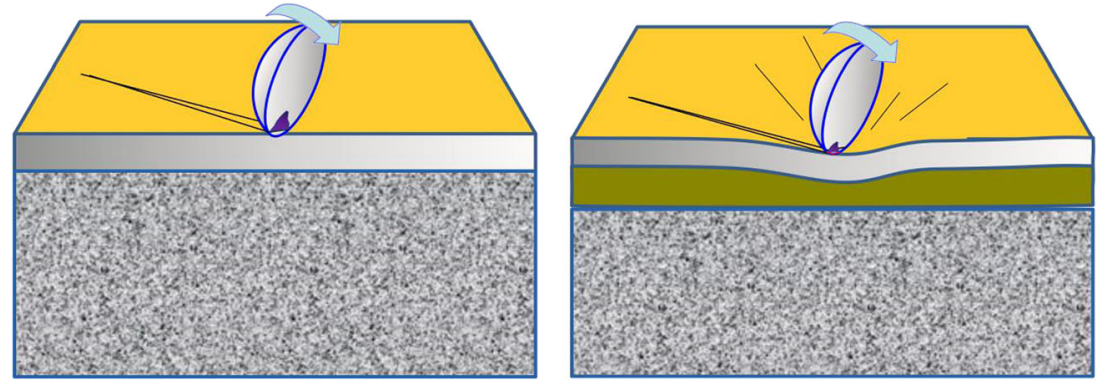

\subsection{Elastic cutting tool materials}

A conclusion which can be drawn is that a more flexible and elastic coating could decrease the abrasive wear rate. With a hard top layer, $\mathrm{Al}_{2} \mathrm{O}_{3}$, in combination with a more elastic thicker layer underneath (see Fig. 19), a cutting edge needs a certain cutting force per edge line to be able to cut. If the edge line or the engagement is too large, it will not cut at all or only along a short engagement arc in the centre of the arc. Gradient sintered grades with binder-enriched surface zones utilize the previously mentioned mechanism.

\subsection{The size}

The size of the hard inclusions is important. Very large hard objects in the work material may quickly ruin the cutting edge. Smaller inclusions wear less even if they all together have the same volume [12]. An explanation could be that they do not split so easily and that the cutting forces pressing the particle fragment towards the tool are lower if we compare them with the larger fragment size (total force from the workpiece material is constant). The smaller inclusions also get hotter than the larger ones and are hence softer.

\subsection{Sand paper}

The cutting tool faces a surface like sandpaper at the surfaces in contact with the workpiece and the chip. The fragments or grains are fed out towards the cutting tool due to large degree of tensile plastic deformation. As shown in the Fig. 10, the deposits at the end of the rip seem to be untouched except when a fragment cuts through them. An explanation could be that the matrix material is only partially in contact with the cutting tool material, like sandpaper with long distances between the grains. This means that there might be a gap between the matrix and the cutting tool. The presence of a gap would, to a high degree, influence the energy transfer between the two surfaces. The energy transfer through the ceramic splinters is low. Another matter is built-up edge (BUE) or deposits on the cutting tool and the workpiece surfaces. Steel with low content of hard inclusions is in general very sticky, which results in deposits on workpiece and tool surfaces.

\subsection{Detection}

A speculation is that we should have a high frequency of vibration, referring to the case with $34 \mathrm{CrNiMo} 6$, around $45 \mathrm{MHz}$. If this is correct, we would get a possible detection method for this type of abrasive wear.

\subsection{First- and second-generation fragments}

A further observation is that the rips form waviness with a first generation of fragments, then a second and so forth [14]. The wavelength, $<0.10 \mathrm{~mm}$, is too short to be emanating from the segmentation of the chip.

\section{Conclusions}

1. This model "spin-split" explains the wear pattern in twobody abrasive wear that often occurs in metal cutting. The real behaviour is, however, more complex, but the model shows a likely mechanism that produces two-body abrasive wear. In line with the model, two-body abrasive wear is a micro cutting process within the main cutting zone.

2. The laboratory study is made on the tool flank, but the wear pattern is the same on both the flank and the rake, so we can assume that the same mechanism is applied on both sides.

3. The results can be used for optimization of the cutting material and the work material.

4. The hard particles in the work material are often a part of the alloy and necessary for the mechanical properties, but they could be made smaller, less brittle or softer at high temperature.

5. The mechanical properties in the coating can be improved and adopted to the particle size to prevent cutting.

Acknowledgements This study has been carried out in collaboration with senior scientists at AB Sandvik Coromant Sweden, Sandvik Material Technology Sweden and Uddeholm AB Sweden. 
Special thanks to Dr. Marianne Collin, her staff and colleagues for excellent laboratory work and engineering support. Furthermore, a great thank to Prof. Lars Nyborg, Chalmers University of Technology, Sweden, for scientific guidance.

Open Access This article is distributed under the terms of the Creative Commons Attribution 4.0 International License (http:// creativecommons.org/licenses/by/4.0/), which permits unrestricted use, distribution, and reproduction in any medium, provided you give appropriate credit to the original author(s) and the source, provide a link to the Creative Commons license, and indicate if changes were made.

\section{References}

1. Standard terminology relating to wear and erosion. Annual book of standards, Vol. 03.02, ASTM, 1987, p 243-250

2. ASM Handbook Committee (2002) ASM handbook, friction, lubrication and wear technology, vol 18. ASM International, USA

3. Ramalingam S, John D (1980) Watson, inclusion chemistry control for machinability enhancement in steels. Mater Sci Eng 43:101108

4. Ramalingam S, Wright PK (1981) Abrasive wear in machining: experiments with materials of controlled microstructure. J Eng Mater Technol 103:151-156
5. Bejjani R, Shi B, Attia H, Balazinski M (2011) Laser assisted turning of titanium metal matrix composite. CIRP Ann Manuf Technol 60(1):61-64 ISSN 0007-8506

6. Byrd JD, Ferguson BL (1978) A study of the influence of hard inclusions on carbide tool wear utilizing a power metal technique. In: Proceedings of the Sixth NAMRC pp 310-315

7. Wong T, Kwon P, Kim W (2004) A predictive model for tool wear on coated inserts. Wear 257(7-8):790-798

8. The cutting tool geometry designations and cutting data designations are according to ISO $3002-1,-2,-3,-4$, and 5

9. Trent EM (2000) Metal Cutting. 4th edn, Butterworth \& Co Ltd. London, England

10. Lorenzo J, Järvstråt N (2009) Modeling the influence of carbides on tool wear. Archives of Computational Materials Science and Surface Engineering 1(1):29-37

11. The material designations are according to EN 10 027-1

12. Thakare MR, Wharton JA, Wood RJK, Menger C (2012) Effect of abrasive particle size and the influence of micro structure on the wear mechanisms in wear-resistant materials. Wear 276:16-28

13. Cozza RC (2014) Third abrasive wear mode: is it possible? J Mater Res Technol 3(2):191-193

14. Park K-H, Kwon PY (2011) Flank wear of multi-layer coated tool. Wear 270:771-780 